\title{
Human red blood cell aging at 5,050-m altitude: a role during adaptation to hypoxia
}

\author{
MICHELE SAMAJA, LAURA BRENNA, SONIA ALLIBARDI, AND PAOLO CERRETELLI \\ Department of Biomedical Sciences and Technologies, Scientific Institute San Raffaele, \\ University of Milano, I-20132 Milan, Italy; and Department of Physiology, \\ Centre Médical Universitaire, 1211 Geneva 4, Switzerland
}

\begin{abstract}
Samaja, Michele, Laura Brenna, Sonia Allibardi, AND PAOLO CERRETELLI. Human red blood cell aging at 5,050-m altitude: a role during adaptation to hypoxia. J. Appl. Physiol. 75(4): 1696-1701, 1993.- To test the hypothesis that the human red blood cell aging process participates actively in the adaptation to hypoxia, we studied some physical and biochemical hematologic variables in 10 volunteers at sea level (SL) and after 1 (1WK) or $5 \mathrm{wk}(5 \mathrm{WK})$ of exposure to 5,050-m altitude. The 2,3-diphosphoglycerate-to-hemoglobin ratio (2,3-DPG/ $\mathrm{Hb})$ was $0.88 \pm 0.03(\mathrm{~mol} / \mathrm{mol})$ at $\mathrm{SL}$ and increased to $1.08 \pm$ $0.03(P=0.002)$ and $1.28 \pm 0.05(P<0.0001)$ at $1 \mathrm{WK}$ and $5 \mathrm{WK}$, respectively. The average red blood cell density $\left(D_{50}\right)$, which is inversely proportional to the fraction of young red blood cells and is therefore an index of the red blood cell aging process, was $1.1053 \pm 0.0007 \mathrm{~g} / \mathrm{ml}$ at SL and decreased to $1.1046 \pm$ $0.0008 \mathrm{~g} / \mathrm{ml}(\mathrm{NS})$ and $1.1018 \pm 0.0008 \mathrm{~g} / \mathrm{ml}(P<0.0001)$ at $1 \mathrm{WK}$ and $5 \mathrm{WK}$, respectively. $\mathrm{D}_{50}$ was correlated with $2,3-\mathrm{DPG} /$ $\mathrm{Hb}$ at SL $(P=0.004)$, only weakly at $5 \mathrm{WK}(P=0.1)$, but not at all at $1 \mathrm{WK}$. The arterial $\mathrm{O}_{2}$ saturation was correlated with the change of $2,3-\mathrm{DPG} / \mathrm{Hb}$ in $1 \mathrm{WK}(P=0.02)$ and that of $\mathrm{D}_{50}$ in $5 \mathrm{WK}(P=0.04)$. It is concluded that short-term (1WK) increase of $2,3-\mathrm{DPG} / \mathrm{Hb}$ is not associated with the erythropoietic response but is presumably due to respiratory alkalosis. By contrast, after prolonged hypoxia $(5 \mathrm{WK})$, erythropoiesis may provide an efficient way for increasing blood 2,3-DPG through an augmented proportion of young red blood cells.
\end{abstract}

\section{2,3-diphosphoglycerate; erythropoiesis}

PRESERVATION OF ADEQUATE TISSUE $\mathrm{O}_{2}$ supply is of critical importance in hypoxia. Circulatory, respiratory, and erythropoietic adjustments are primarily involved in the acclimatization process $(2,19,31,34)$. An important functional role may also be attributed to the increased affinity for $\mathrm{O}_{2}$ of the red blood cell (RBC) by way of higher 2,3-diphosphoglycerate (2,3-DPG) concentration $(13,14)$. Hyperventilation-induced alkalosis (21) appears to trigger the initial increase of 2,3-DPG through stimulation of RBC phosphofructokinase $(5,8,13)$. However, the discrepancy in change between blood $\mathrm{pH}$, which returns to near normal values in a few days (16) [although never completely (18)], and [2,3-DPG], which remains high, suggests alternative mechanisms regulating [2,3-DPG] in sojourners and altitude natives.

The mature RBC is unable to perform certain functions that normally occur in most aerobic cells, including the synthesis of proteins and the generation of energy from oxidative processes requiring $\mathrm{O}_{2}$. The inability to repair extensive damage, such as unbalanced metabolism or altered ion homeostasis, confers on the human RBC the unique characteristics of a limited 120-day life span, as assessed by ${ }^{59} \mathrm{Fe}$ tagging $(1,6)$ and carbon monoxide rebreathing (29) techniques. This imposes the set point between the production of new RBCs by the bone marrow and their removal from the circulation by the reticuloendothelial system. The latter process occurs at random in some animal species but is selective for aging RBCs in humans (4). Old RBCs are characterized by reduced deformability (15), altered intracellular $\mathrm{Ca}^{2+}$ handling (25), and energy depletion $(3,12,28)$. Two important features of these alterations are 1) the progressive inactivation of the membrane $\mathrm{Na}^{+}-\mathrm{K}^{+}$-adenosinetriphosphatase, leading to cell shrinking without alteration of its content, and 2) the progressive reduction of the $\mathrm{RBC}$ concentration of 2,3-DPG during $\mathrm{RBC}$ aging, with associated increase of the RBC- $\mathrm{O}_{2}$ affinity $(10,24,27)$. Although the former feature allows an estimation of the $\mathrm{RBC}$ age from its density, the latter provides an attractive explanation for the high [2,3-DPG] found at altitude both in sojourners and natives. Indeed, it may be hypothesized that the stimulation of erythropoiesis by hypoxia also increases the fraction of young RBCs characterized by high 2,3-DPG levels, but so far little experimental evidence supports this hypothesis.

$\mathrm{RBC}$ aging was recently correlated with $\mathrm{O}_{2}$ affinity in some subgroups of a healthy human population. It was shown that the high [2,3-DPG] needed to compensate some anemic situations was conveniently met by lowering of the average age of the circulating RBCs (24). Thus, the $\mathrm{RBC}$ aging process actively participates in the adaptation to anemia (23).

The aim of the present investigation was to test the hypothesis that the RBC turnover is relevant also in response to chronic hypoxia. For this purpose, we assessed $\mathrm{RBC}$ aging from measurement of density and altituderelated changes of several hematologic variables in a group of volunteers during altitude acclimatization. In addition, we compared these data with those obtained in a group of local altitude natives. Possible cause-effect relationships between the stimulus (hypoxia) and the responses (increase of 2,3-DPG, decrease of average RBC density) were investigated, correlating the changes of [2,3-DPG] and $\mathrm{RBC}$ age with the $\mathrm{O}_{2}$ saturation of arterial blood $\left(\% \mathrm{Sa}_{\mathrm{O}_{2}}\right)$. 
MATERIALS AND METHODS

Subjects. A first group of 10 Caucasian volunteers (8 males and 2 females) was studied at sea level (SL) 2 mo before departure and after $1(1 \mathrm{WK})$ and $5 \mathrm{wk}(5 \mathrm{WK})$ of exposure to $5,050 \mathrm{~m}$ (average barometric pressure 420 Torr). All subjects [age $35.5 \pm 3.4$ (SE) yr] were normally living at altitudes $<300 \mathrm{~m}$ and had no symptoms of metabolic or blood disorders. The subjects arrived at the EvK2 Pyramid laboratory located at 5,050 m near the base camp of Mt. Everest (Nepal) after 1 wk of trekking at altitudes ranging from 2,600 to $5,050 \mathrm{~m}$ to allow proper acclimatization. Apart from some discomfort in the days after arrival at 5,050 m, none of the subjects experienced symptoms of mountain sickness. Unlimited palatable caloric and water intake decreased the body weight loss to $0.7 \%(\mathrm{NS})$ and $4.6 \%(P<0.05)$ after 1 and 5 wk at altitude, respectively (20). The physical and mental activities after reaching the laboratory were comparable to those of normal life.

A second group of local male natives (NAT, $n=10$, age $24.1 \pm 1.8 \mathrm{yr}$ ), dwelling at altitudes ranging from 1,300 to $2,800 \mathrm{~m}$ but occasionally residing at $5,050 \mathrm{~m}$ for $1-3 \mathrm{wk}$, also participated in the study.

Blood samples. Venous blood $(3 \mathrm{ml})$ was withdrawn at rest from an antecubital vein into heparinized syringes or vacutainers and immediately chilled in an ice bath. Some of the analyses required immediate processing, and most of the operations described below were performed within 10 min after withdrawal unless otherwise stated.

$R B C$ density profiles. The technique employed to determine the RBC density profiles of the samples was described previously (24). Briefly, a stock hyperosmotic solution containing $2.66 \mathrm{M} \mathrm{NaCl}$ and $0.09 \mathrm{M} \mathrm{KCl}$ was prepared. Two isotonic solutions were obtained daily, mixing $5.5 \mathrm{vol}$ of the hyperosmotic solution with either 65 or 88 vol of Percoll (Sigma Chemical, St. Louis, MO) and balancing to 100 vol with deionized water to yield densities of 1.090 and $1.120 \mathrm{~g} / \mathrm{ml}$, respectively. Intermediate densities were obtained, mixing in appropriate ratios the above two solutions. The density gradient profiles were obtained using 10 solutions with increasing density in $0.003-\mathrm{g} / \mathrm{ml}$ steps.

Small centrifuge tubes ( $4 \mathrm{~mm}$ ID $\times 39 \mathrm{~mm}$ long) were loaded with $0.15 \mathrm{ml}$ of the isotonic solution with the desired density. Fresh blood $(0.05 \mathrm{ml})$ was carefully layered over them. The tubes were immediately centrifuged at $12,000 \mathrm{rpm}$ for $2 \mathrm{~min}$. After centrifugation, the blood layers above and below the Percoll were recovered by a syringe and diluted separately in accurately dispensed 5 $\mathrm{ml}$ Drabkin's reagent (nominal accuracy $\pm 0.01 \mathrm{ml}$ ). The two solutions were labeled "top" and "bottom," respectively. Their optical absorbance (A) was measured in a 1-cm path length cuvette at $540 \mathrm{~nm}$ after $60-120 \mathrm{~min}$ of incubation at room temperature. The ratio $\mathrm{A}_{\text {top }} /\left(\mathrm{A}_{\text {top }}+\mathrm{A}_{\text {bottom }}\right)$ yields the fraction of $\mathrm{RBC}$ lighter than the actual density of the Percoll solution. This value was used to build the density vs. light RBC curves shown in Fig. 1.

Perchloric acid extracts. Immediately ( $\leq 1 \mathrm{~min})$ after withdrawal, $0.25 \mathrm{ml}$ blood was extracted with $0.6 \mathrm{ml}$ of 1 $M$ perchloric acid, chilled in an ice bath for $5 \mathrm{~min}$, and

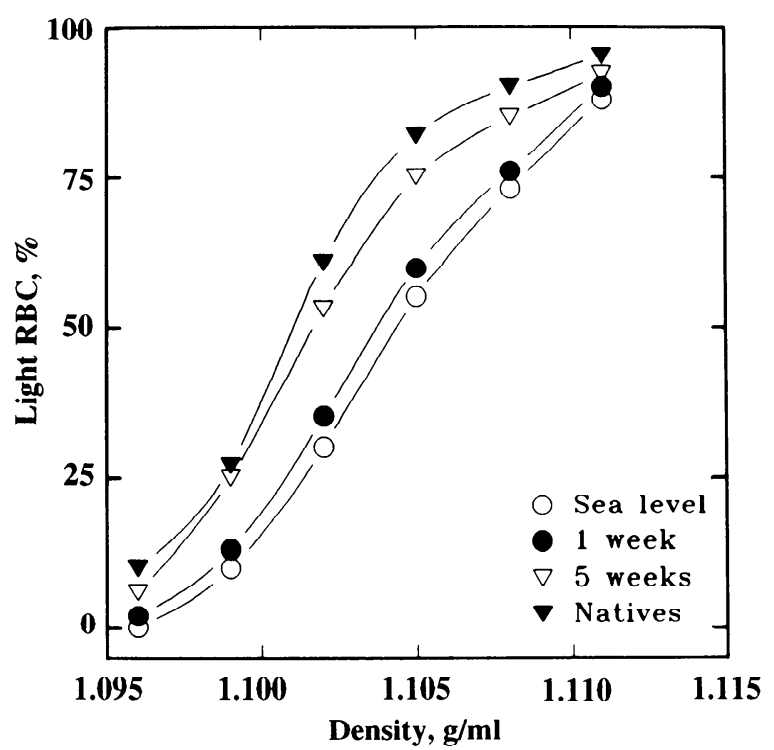

FIG. 1. Red blood cell (RBC) density profiles in 4 groups under study. Each curve is representative of 10 different subjs. Error bars are omitted for clarity.

spun at $12,000 \mathrm{rpm}$ for $3 \mathrm{~min}$. Four hundred microliters of the supernatant were neutralized with $0.1 \mathrm{ml}$ of neutralizing solution containing $0.5 \mathrm{M} \mathrm{KOH}$ and $1 \mathrm{M}$ $\mathrm{KH}_{2} \mathrm{PO}_{4}, \mathrm{pH} 7$, and were frozen to $-30^{\circ} \mathrm{C}$. In this form, the samples were shipped to the laboratory in Milan for high-performance liquid chromatographic analysis of ATP. Preliminary experiments (not shown) indicated that the extracts neutralized as described above remained stable for $\geq 2 \mathrm{mo}$. The high-performance liquid chromatographic equipment (Kontron Instruments, Milan, Italy) was composed of two pumps (model 420) and a detector (model $432, \mathrm{UV} / \mathrm{Vis}$ ) set at $210 \mathrm{~nm}$. The $3-\mu \mathrm{m}$ Supelcosil LC18 column (Supelco, Bellefonte, PA) was

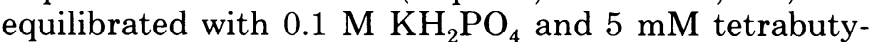
lammonium sulfate, and the sample $(20 \mu \mathrm{l})$ was injected and eluted using a composed gradient with a buffer containing $0.1 \mathrm{M} \mathrm{KH}_{2} \mathrm{PO}_{4}, 4 \mathrm{mM}$ tetrabutylammonium sulfate, and $90 \%$ (vol/vol) $\mathrm{CH}_{3} \mathrm{CN}$. The analysis was completed in $25 \mathrm{~min}$, and data were analyzed with the Kontron's dedicated software against a blank.

An additional acid extract was prepared on fresh blood to measure [2,3-DPG] with the kits supplied by Boehringer Biochemia (Mannheim, Germany) within $2 \mathrm{~h}$ of withdrawal. 2,3-DPG is expressed as the molar ratio of [2,3-DPG] to hemoglobin concentration ([Hb]).

Additional measurements. Percent $\mathrm{Sa}_{\mathrm{O}_{2}}$ was measured at rest by ear oximetry (Biox 3740 pulse oximeter, $\mathrm{Oh}$ meda). Blood $[\mathrm{Hb}]$ was determined with the standard Drabkin method of reading the absorbance at $540 \mathrm{~nm}$ (Spectronic 301, Milton Roy, Rochester, NY) and was standardized by calibrating the diluent volumes with a balance. Erythropoietin (EPO) was assayed in Milan on frozen serum samples with a standard laboratory assay kit (Milenia, Medical Systems, Genoa, Italy).

Calculations and statislical tests. The RBC density gradient profiles were expressed quantitatively by a single parameter interpolating the density at which the light RBC fraction is $50 \%$ of the total $\left(D_{50}\right)$. For this purpose, least-square fitting to empirical functions (TableCurve 
TABLE 1. Hematologic variables in 10 subjs at sea level and after 1 and 5 wk of exposure to altitude

\begin{tabular}{|c|c|c|c|c|c|c|c|c|c|c|c|c|c|c|c|c|c|c|}
\hline \multirow[b]{2}{*}{ Subject } & \multicolumn{3}{|c|}{$\begin{array}{c}{[\mathrm{Hb}]} \\
\mathrm{g} / \mathrm{l}\end{array}$} & \multicolumn{3}{|c|}{$\begin{array}{c}{[2,3-\mathrm{DPG}] /[\mathrm{Hb}]} \\
\mathrm{mol} / \mathrm{mol}\end{array}$} & \multicolumn{3}{|c|}{$\begin{array}{c}{[\mathrm{ATP}] /[\mathrm{Hb}]} \\
\mathrm{mol} / \mathrm{mol}\end{array}$} & \multicolumn{3}{|c|}{$\begin{array}{l}\mathrm{D}_{50} \\
\mathrm{~g} / \mathrm{ml}\end{array}$} & \multicolumn{3}{|c|}{$\begin{array}{l}\mathrm{FPO}, \\
\mathrm{mU} / \mathrm{ml}\end{array}$} & \multicolumn{3}{|c|}{$\begin{array}{c}\mathrm{Sa}_{\mathrm{O}_{2}} \\
\%\end{array}$} \\
\hline & SL & $1 \mathrm{WK}$ & $5 \mathrm{WK}$ & $\mathrm{SL}$ & $1 \mathrm{WK}$ & $5 \mathrm{WK}$ & $\mathrm{SL}$ & $1 \mathrm{WK}$ & $5 \mathrm{WK}$ & SL & $1 \mathrm{WK}$ & $5 \mathrm{WK}$ & SL & $1 W K$ & $5 \mathrm{WK}$ & SL & $1 \mathrm{WK}$ & $5 \mathrm{WK}$ \\
\hline$L B$ & 141.7 & 203.5 & 174.6 & 0.98 & 1.10 & 1.45 & 0.221 & 0.242 & 0.283 & 1.1031 & 1.1033 & 1.0982 & 17.1 & 17.7 & 17.8 & & 83 & 86 \\
\hline$F C$ & 157.8 & 190.4 & 185.6 & 0.92 & 0.93 & 1.37 & 0.233 & 0.247 & 0.236 & 1.1067 & 1.1013 & 1.1024 & 11.8 & 54.0 & 62.0 & & 83 & 79 \\
\hline$A C$ & 157.8 & 214.9 & 197.7 & 0.96 & 1.05 & 1.30 & 0.187 & 0.188 & 0.224 & 1.1043 & 1.1017 & 1.0990 & 11.9 & 13.0 & 17.0 & & 85 & 80 \\
\hline$F E$ & 156.2 & 206.8 & 195.9 & 0.78 & 1.10 & 1.13 & 0.217 & 0.216 & 0.261 & 1.1067 & 1.1056 & 1.1024 & 14.3 & 67.0 & 25.0 & & 82 & 81 \\
\hline$B G$ & 162.6 & 227.3 & 212.3 & 0.92 & 1.02 & 1.10 & 0.168 & 0.215 & 0.252 & 1.1047 & 1.1061 & 1.1038 & 14.6 & 38.0 & 33.0 & & 90 & 93 \\
\hline$B K$ & 156.2 & 179.4 & 183.4 & 0.74 & 1.27 & 1.32 & 0.261 & 0.204 & 0.233 & 1.1085 & 1.1048 & 1.1053 & 14.2 & 20.0 & 16.0 & & 77 & 81 \\
\hline$S M$ & 143.3 & 196.2 & 182.7 & 1.04 & 1.18 & 1.58 & 0.187 & 0.204 & 0.324 & 1.1014 & 1.1013 & 1.0997 & 5.0 & 14.2 & 13.5 & & 83 & 84 \\
\hline$M N$ & 156.2 & 209.8 & 204.3 & 0.72 & 0.95 & 1.08 & 0.269 & 0.265 & 0.268 & 1.1073 & 1.1076 & 1.1047 & 15.9 & 34.0 & 25.0 & & 82 & 83 \\
\hline$A R$ & 169.1 & 215.3 & 205.7 & 0.81 & 1.16 & 1.11 & 0.191 & 0.230 & 0.249 & 1.1044 & 1.1075 & 1.1007 & & & & & 74 & 82 \\
\hline$H S$ & 150.5 & 190.0 & 181.9 & 0.92 & 1.03 & 1.34 & 0.190 & 0.141 & 0.251 & 1.1058 & 1.1064 & 1.1018 & & & & & 82 & 84 \\
\hline Mean & 155.1 & 203.4 & 192.4 & 0.88 & 1.08 & 1.28 & 0.212 & 0.215 & 0.258 & 1.1053 & 1.1046 & 1.1018 & 13.1 & 32.2 & 26.2 & & 82 & 83 \\
\hline$\pm \mathrm{SE}$ & \pm 2.6 & \pm 4.6 & \pm 3.9 & \pm 0.03 & \pm 0.03 & \pm 0.05 & \pm 0.011 & \pm 0.011 & \pm 0.009 & \pm 0.0007 & \pm 0.0008 & \pm 0.0008 & \pm 1.3 & \pm 7.0 & \pm 5.6 & & \pm 1 & \pm 1 \\
\hline$P$ & & $<0.0001$ & $<0.0001$ & & 0.002 & $<0.0001$ & & NS & 0.01 & & NS & $<0.0001$ & & 0.02 & 0.008 & & & \\
\hline
\end{tabular}

Values are raw data and means $\pm \mathrm{SE}$ of Caucasian subjs at sea level (SL) and after 1 (1WK) and $5 \mathrm{wk}(5 \mathrm{WK})$ of exposure to $5,050 \mathrm{~m}$. [Hb], hemoglobin concn; [2,3-DPG], 2,3-diphosphoglycerate concn; $\mathrm{D}_{50}$, average $\mathrm{RBC}$ density; $\mathrm{EPO}$, erythropoietin; $\mathrm{Sa}_{\mathrm{O}_{2}}$, arterial $\mathrm{O}_{2}$ saturation; $P$, significance of differences from SL (by Wilcoxon signed-rank test). $\mathrm{EPO}$ data for 2 subjs and $\mathrm{Sa}_{\mathrm{O}_{2}}$ data at SL, were not obtained.

software, Jandel Scientific, Corte Madera, CA) was used to determine $D_{50}$ for each subject from the density vs. light RBC plots. To compare data obtained from the same subjects at various times, the nonparametric Wilcoxon signed-rank test was used. To compare two different populations, the nonparametric Mann-Whitney test for unpaired samples was used. The significance level was set at $P=0.05$ (2-tailed).

\section{RESULTS}

Figure 1 shows typical RBC density gradient curves for the two groups under study at the investigated exposure conditions. Sojourning at altitude resulted in decreased $\mathrm{RBC}$ density. Local natives exhibited the lowest RBC density. The slopes of the density curves were essentially equal in their middle portion. Therefore, the $\mathrm{D}_{50}$ was a good estimate of the average RBC density and a criterion for characterizing the groups.

In Table 1, raw data of the subjects at SL before departure and after $1 \mathrm{WK}$ and $5 \mathrm{WK}$ of exposure to altitude are reported. All parameters were altered by hypoxia, but the changes of $[\mathrm{Hb}],[2,3-\mathrm{DPG}] /[\mathrm{Hb}], \mathrm{EPO}$, and $\% \mathrm{Sa}_{\mathrm{O}_{2}}$ occurred more rapidly than those of $[\mathrm{ATP}] /[\mathrm{Hb}]$ and $\mathrm{D}_{50}$ (Fig. 2). It is possible that some degree of dehydration contributed to the abrupt increase of $[\mathrm{Hb}]$ in the 1 st wk. Figure 2 also reports the values found in local natives, with the significance of the differences between them and SL or $5 \mathrm{WK}$ values. $[\mathrm{ATP}] /[\mathrm{Hb}]$ in NAT was near that of SL. For all other parameters, the values of NAT were close to those of $5 \mathrm{WK}$. In separate experiments at SL, no effects of the dietary state of the subjects were noted on the measured variables (not shown).

If young $\mathrm{RBCs}$ are assumed to have high [2,3-DPG],
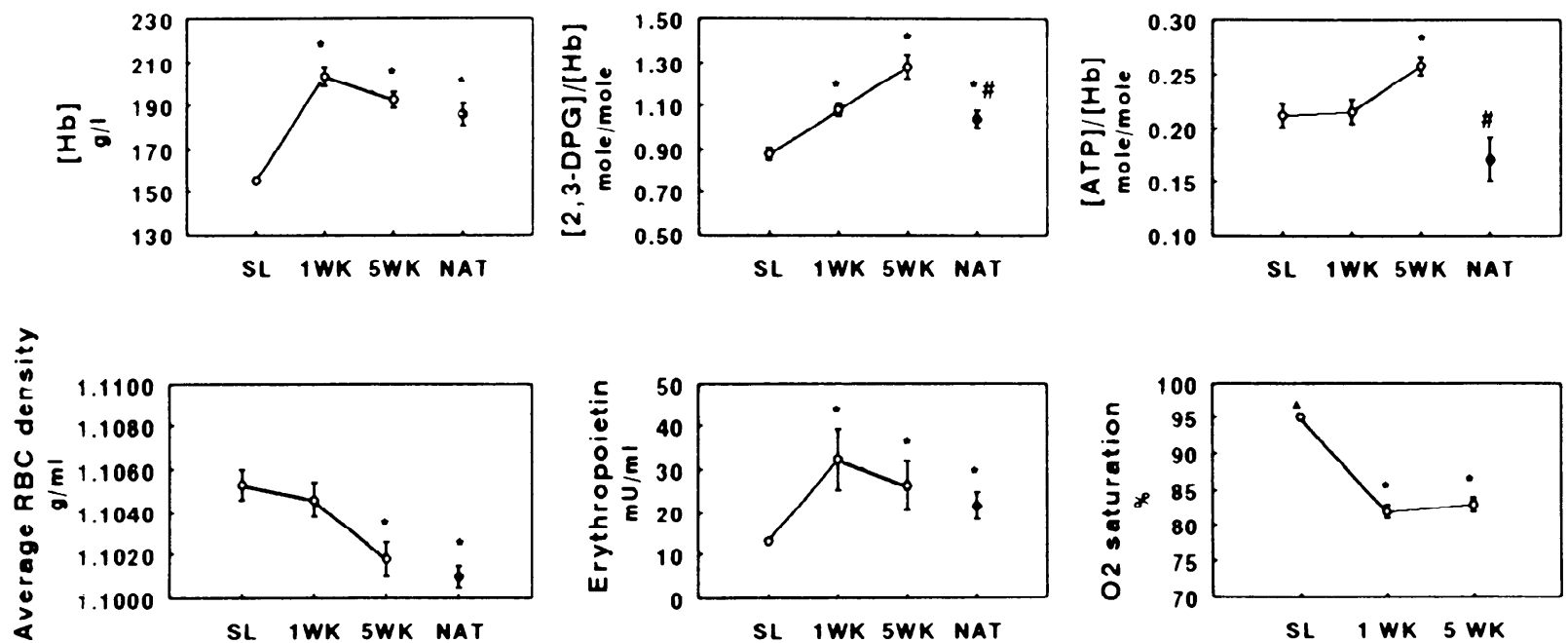

FIG. 2. Kinetics of changes of various parameters in Caucasian subjs at sea level (SL) and on exposure to $5,050 \mathrm{~m}$ for $1(1 \mathrm{WK})$ and $5 \mathrm{wk}(5 \mathrm{WK})$, respectively, and in local natives (NAT). [Hb], hemoglobin concn, [2,3-DPG], 2,3-diphosphoglycerate concn. $\star$ Value for arterial $\mathrm{O}_{2}$ saturation at $\mathrm{SL}$ was assumed and was not measured in NAT. ${ }^{*}$ Significantly different from SL. (Wilcoxon signed-rank and Mann-Whitney tests for unpaired samples were used for Caucasians and NAT, respectively); \# significantly different from 5 WK (for NAT only). 


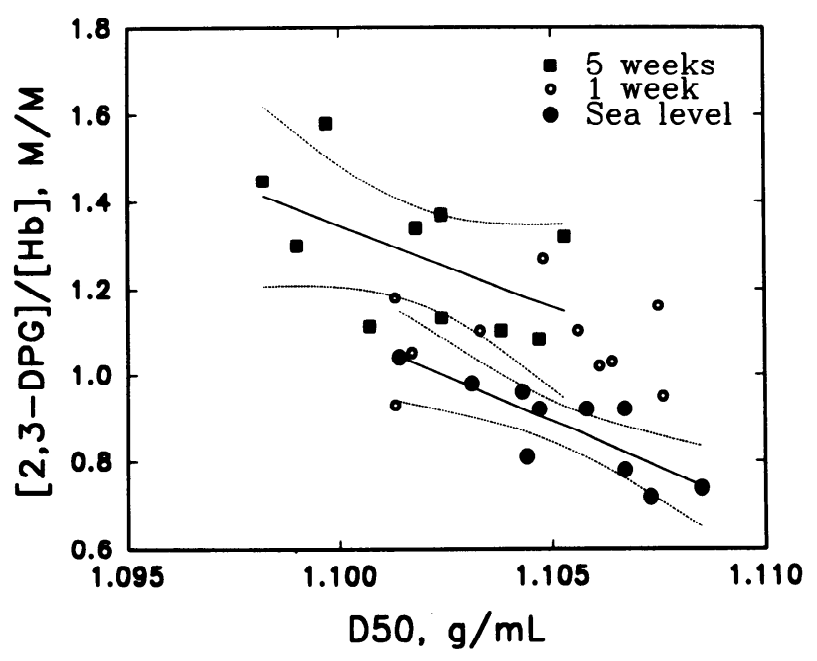

FIG. 3. Relationship between $[2,3-\mathrm{DPG}] /[\mathrm{Hb}]$ ratio and average RBC density $\left(\mathrm{D}_{50}\right)$ at SL, $1 \mathrm{WK}$, and $5 \mathrm{WK}$. Statistically significant correlations were found at SL and 5 WK. Best-fit lines, drawn with $95 \%$ confidence limits, are $y=-40.9 x+46.1, r=0.82, P<0.01$ (SL) and $y=$ $-39.3 x+44.6, r=0.55, P=0.102(5 \mathrm{WK})$. SDs for slope values were 10.3 and 21.3 , respectively.

then a statistically significant correlation of [2,3-DPG]/ $[\mathrm{Hb}]$ with $\mathrm{D}_{50}$ is expected. When all data obtained on Caucasians were pooled, the line of best fit was $y=$ $-41.3 x+46.7$ ( $n=30, r=0.63, P=0.0002$, not shown). However, it is of greater interest to correlate $D_{50}$ with $[2,3-\mathrm{DPG}] /[\mathrm{Hb}]$ within each group, although the smaller number of data points inevitably reduces the significance of the statistical analysis. $\mathrm{D}_{50}$ was rather well correlated with $[2,3-\mathrm{DPG}] /[\mathrm{Hb}]$ at $\mathrm{SL}(P=0.0045)$ but not at $1 \mathrm{WK}$. The correlation tended to improve in $5 \mathrm{WK}(P=0.102$, Fig. 3).

To test the hypothesis that hypoxia or an hypoxia-related factor is involved in the alterations of [2,3-DPG]/ $[\mathrm{Hb}]$ and $\mathrm{D}_{50}$, the size of these changes with respect to SL was correlated with the measured $\% \mathrm{Sa}_{\mathrm{O}_{2}}$ at altitude (Fig. 4). Percent $\mathrm{Sa}_{\mathrm{O}_{2}}$ was negatively correlated with the change of $[2,3-\mathrm{DPG}] /[\mathrm{Hb}]$ at $1 \mathrm{WK}(P=0.022)$, i.e., the lower the $\% \mathrm{Sa}_{\mathrm{O}_{2}}$, the greater the change in $[2,3-\mathrm{DPG}] /$ $[\mathrm{Hb}]$. The significant correlation of $[2,3-\mathrm{DPG}] /[\mathrm{Hb}]$ with $\% \mathrm{Sa}_{\mathrm{O}_{2}}$ was lost at $5 \mathrm{WK}$. On the other hand, there was no correlation of $\mathrm{D}_{50}$ with $\% \mathrm{Sa}_{\mathrm{O}_{2}}$ at $1 \mathrm{WK}$, but a significant correlation between these two variables was detected at $5 \mathrm{WK}(P=0.041)$. No correlation was detected between $\% \mathrm{Sa}_{\mathrm{O}_{2}}$ and [Hb], EPO, or [ATP] (not shown).

\section{DISCUSSION}

The investigated metabolic functions of the human $\mathrm{RBC}$ were influenced by altitude. However, the time course of the changes was different. Acute (1WK) exposure to $5,050 \mathrm{~m}$ primarily affected [2,3-DPG], [Hb], $\% \mathrm{Sa}_{\mathrm{O}_{2}}$, and EPO. The RBC density and [ATP], both indexes of the average $\mathrm{RBC}$ age (28), were influenced by prolonged exposure to hypoxia (5WK).

Decreased RBC density was associated with greater fraction of circulating young RBCs on the basis of the following assumptions (26): 1) RBCs emerge from the bone marrow as a homogeneous population, 2) RBCs are uniformly stressed by hypoxia, 3) the degree of the physical stress to which the RBCs are exposed is proportional to the strength of the stressing agents, and 4) the generated morphological changes are accompanied by proportional functional alterations. Thus, there are at least two reasons for the apparent increase of a younger RBC population: either the stressing factors become less effective, with a consequent reduction of the $\mathrm{RBC}$ aging rate, or the augmented erythropoiesis stimulates the production of new RBCs by the bone marrow. Although we lack direct evidence for either of the above mechanisms, we tend to exclude the former because it is not likely that a physiological stressing factor such as hypoxia decreases its effects during altitude adaptation. In contrast, the observed early increase of EPO and [ $\mathrm{Hb}]$ after the 1st wk at $5,050 \mathrm{~m}$ favors the latter possibility. This hypothesis is consistent with the observed larger mobilization of iron in acute (5-day) exposure to 4,559 $\mathrm{m}$ (17). Normalization of EPO levels during prolonged exposure to altitude has already been reported $(7,9,11,30,36)$.

Young RBCs are characterized by high [2,3-DPG]/ [Hb] (24). Although we did not measure 2,3-DPG in density-separated RBCs, there are no reasons to believe that this relationship should fail at altitude. Therefore, the negative correlation between $\mathrm{D}_{50}$ and $[2,3-\mathrm{DPG}] /[\mathrm{Hb}]$ in $\mathrm{SL}$ and $5 \mathrm{WK}$ values is not surprising. However, the univocal relationship between $[2,3-\mathrm{DPG}] /[\mathrm{Hb}]$ and $\mathrm{D}_{50}$ was missing after $1 \mathrm{wk}$ at $5,050 \mathrm{~m}$, most likely because [2,3$D P G]$ was increased by factors other than decreased $D_{50}$ or RBC aging (see below). The effect of this confounding agent(s) was progressively blunted after 5 wk at $5,050 \mathrm{~m}$ when the relationship between $[2,3-\mathrm{DPG}] /[\mathrm{Hb}]$ and $\mathrm{D}_{50}$ was reestablished. However, the relatively low significance of the relationship between $[2,3-\mathrm{DPG}] /[\mathrm{Hb}]$ and $\mathrm{D}_{50}$ in $5 \mathrm{WK}$ values indicates that the blunting effect was still not completely offset. In fact, in this study, a steadystate condition in the process of hypoxia adaptation was never reached. [ATP] correlated weakly with $\mathrm{D}_{50}$, but

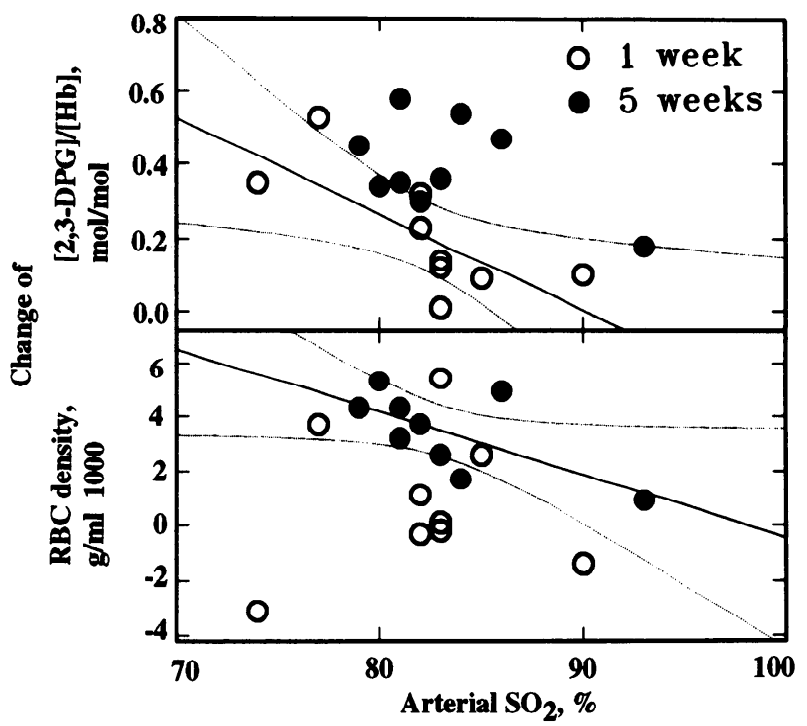

FIG. 4. Correlation of \%arterial $\mathrm{O}_{2}$ saturation $\left(\% \mathrm{Sa}_{\mathrm{O}_{2}}\right)$ with $[2,3-$ $\mathrm{DPG}] /[\mathrm{Hb}]($ top $)$ or $\mathrm{D}_{50}$ (bottom) at $1 \mathrm{WK}$ and $5 \mathrm{WK}$. [2,3-DPG]/[Hb] and $\% \mathrm{Sa}_{\mathrm{O}}$, were correlated in $1 \mathrm{WK}$ but not in $5 \mathrm{WK}$ group. However, $\mathrm{D}_{50}$ and $\% \mathrm{Sa}_{\mathrm{O}_{2}}$ were correlated in $5 \mathrm{WK}$ but not in $1 \mathrm{WK}$ group. Best-fit lines, shown with $95 \%$ confidence limits, are, for $[2,3-\mathrm{DPG}] /[\mathrm{Hb}]$ in $1 \mathrm{WK}, y=-2.6 \times 10^{-2} x+2.36, r=0.71, P=0.022$ and, for $\mathrm{D}_{50}$ in $5 \mathrm{WK}$, $y=2.3 \times 10^{-4} x-0.025, r=0.65, P=0.041$. SDs of slopes were $9 \times 10^{-3}$ and $9.4 \times 10^{-5}$, respectively. 
this feature could be expected because of the small decrease of $[\mathrm{ATP}]$ in the aging $\mathrm{RBC}(10)$.

The relationships of $\% \mathrm{Sa}_{\mathrm{O}_{2}}$ with the changes of [2,3$\mathrm{DPG}] /[\mathrm{Hb}]$ and $\mathrm{D}_{50}$ indicate that 1-wk altitude exposure increases $[2,3-\mathrm{DPG}] /[\mathrm{Hb}]$ by mechanisms not mediated by erythropoiesis but sensitive to $\% \mathrm{Sa}_{\mathrm{O}_{2}}$, presumably hyperventilation-mediated alkalosis (21). For prolonged (5-wk) exposures, enhanced erythropoiesis should have increased the relative fraction of young $\mathrm{RBCs}$, thereby raising average blood [2,3-DPG] by mechanisms independent of the body acid-base status. This stimulation appears sensitive to $\% \mathrm{Sa}_{\mathrm{O}_{2}}$, like the former, but acts on a longer time scale, of the same order of magnitude as that of the life span of the circulating RBCs (120 days) $(1,6)$. An alternative hypothesis for the increased [2,3-DPG]/ [Hb] in hypoxia possibly involves enhanced binding of 2,3-DPG to $\mathrm{Hb}$ as a result of the increased fraction of deoxygenated $\mathrm{Hb}$. However, serious doubt has been cast on the validity of the latter hypothesis (5).

Conclusions. Altitude exposure induces physiological and biochemical changes aimed at maintaining adequate tissue oxygenation despite reduced $\mathrm{O}_{2}$ tension. A reduced $\mathrm{RBC}-\mathrm{O}_{2}$ affinity is considered useful up to $5,500 \mathrm{~m}$ for improving the $\mathrm{O}_{2}$ transport without overloading the circulation, particularly at moderate work loads $(23,24)$. Although this response becomes disadvantageous at higher altitude or at heavy work (22), the deleterious effects of polycythemia at altitude have been well documented $(32,34,35)$. In general, whereas the low sensitivity of the $\mathrm{RBC}$ metabolic pathways to $\mathrm{PO}_{2}$ changes is actually a positive feature for an $\mathrm{O}_{2}$ carrier, this does not imply that the RBC is excluded from active participation in the organism's response to hypoxia: a series of responses and feedback mechanisms are activated, leading eventually to increased [2,3-DPG]/[Hb]. These mechanisms are related both to the hypoxia-driven alkalosis and to the rejuvenation of the $\mathrm{RBC}$ population. This last feature would indicate that the $\mathrm{RBC}$ is not an inert $\mathrm{O}_{2}$ carrier but may also have a substantial role in the process of $\mathrm{O}_{2}$ transport during altitude acclimatization. The occurrence of such mechanisms in different geographic areas (33) and in cases of pathological hypoxia that do not directly involve $\mathrm{Hb}$ or the RBC (cardiac congenital disease, chronic obstruction of the lungs) is still matter for investigation.

This study was performed as a part of the Ev-K2 Project, Milan, Italy. We gratefully acknowledge the Ev-K2 Committee, Mountain Equipe, and all the personnel of the Pyramid Laboratory who made this work possible. We also acknowledge the helpful suggestions provided by Drs. Bengt Kayser, Claudio Marconi, and Marco Narici.

This study was supported in part by a Target Project Biotechnology and Bioinstrumentation grant, Rome, Italy.

Address for reprint requests: M. Samaja, Università di Milano, Dipartimento di Scienze e Tecnologie Biomediche, Istituto Scientifico San Raffaele, via Olgettina 60, I-20132 Milan, Italy.

Received 28 December 1992; accepted in final form 24 May 1993.

\section{REFERENCES}

1. Borun, E. R., W. G. Figueroa, And S. M. Perry. The distribution of $\mathrm{Fe}^{59}$ tagged human erythrocytes in centrifuged specimens as a function of cell age. J. Clin. Invest. 36: 676-679, 1957.

2. Cerretelli, P. Gas exchange at high altitude. In: Pulmonary Gas Exchange. New York: Academic, 1980, p. 97-147.
3. Chapman, R. G., And L. Schaunburg. Glycolysis and glycolytic enzymes activity of aging red cell in man. Br. J. Haematol. 13: 665678, 1967.

4. ClaAk, M. R. Senescence of red blood cells: progress and problems. Physiol. Rev. 68: 503-554, 1988.

5. Duhm, J., AND E. Gerlach. On the mechanism of the hypoxia-induced increase of 2,3-diphosphoglycerate in erythrocytes. Pfluegers Arch. 326: 254-269, 1971.

6. EADIE, G. S., AND I. W. BRown. Red blood cell survival studies. Blood 8: 1110-1136, 1953.

7. ERslev, A. J., J. CARo, O. Miller, ANd R. Silver. Plasma erythropoietin in health and disease. Ann. Clin. Lab. Sci. 10: 250-257, 1980.

8. Espinos, S. D., D. J. Alvarez-Sola, AND A. Villegas. Relationship of red cell 2,3-diphosphoglycerate with anemia, hypoxaemia and acid-base status in patients with cirrhosis of the liver. Scand. J. Clin. Lab. Invest. 42: 613-616, 1982.

9. FAurA, J. Effect of altitude on erythropoiesis. Blood 33: 668-676, 1969.

10. Haidas, S., D. LABIE, AND J. C. KAPLAN. 2,3-Diphosphoglycerate content and oxygen affinity as a function of red cell age in normal individuals. Blood 38: 463-467, 1971.

11. JelkmanN, W., A. KurTz, J. SeidL, AND C. Bauer. Temporal pattern of erythropoietin titers in kidney tissue during hypoxic hypoxia. Pfluegers Arch. 393: 88-91, 1982.

12. KADLUBOVSKI, M., AND P. S. AGUTTER. Changes in the activities of some membrane-associated enzymes during in vivo ageing of the normal human erythrocyte. Br. J. Haematol. 37: 111-125, 1977.

13. Lenfant, C., J. D. Torrance, and C. Reynafarde. Shift of the $\mathrm{O}_{2}-\mathrm{Hb}$ dissociation curve at altitude: mechanism and effect. $J$. Appl. Physiol. 30: 625-631, 1971.

14. Lenfant, C., J. D. Torrance, R. D. Woodson, P. Jacobs, and C. A. FINCH. Role of organic phosphates in the adaptation of man to hypoxia. Federation Proc. 29: 1115-1117, 1970.

15. LinderKamP, O., AND H. J. Meiselman. Geometric-osmotic and membrane mechanical properties of density-separated human red cells. Blood 59: 1121-1127, 1982.

16. Lozano, R., C. Torres, C. Marchena, J. Whittenburg, and C. C. Monge. Response to metabolic (ammonium chloride) acidosis at sea level and at high altitude. Nephron 6: 102-109, 1969.

17. Mairbäurl, H., W. Schobersberger, O. Oelz, P. Bärtsch, K. U. ECKARDT, AND C. BAUER. Unchanged in vivo $P_{50}$ at high altitude despite decreased erythrocyte age and elevated 2,3-diphosphoglycerate. J. Appl. Physiol. 68: 1186-1194, 1990.

18. Milledge, J. S., AND S. LAHIRI. Respiratory control in lowlanders and Sherpa highlanders at altitude. Respir. Physiol. 2: 310-322, 1967.

19. Monge, C. C., and F. Leon-Velarde. Physiological adaptation to high altitude: oxygen transport in mammals and birds. Physiol. Rev. 71: 1135 1172, 1991.

20. Narici, M. V., B. Kayser, L. Landoni, AND P. Cerretelli. Effect of chronic hypoxia on work-induced human skeletal muscle hypertrophy (Abstract). J. Physiol. Lond. 467: 109P, 1993.

21. RAHN, H., AND A. B. OTIS. Man's respiratory response during and after acclimatization to high altitude. Am. J. Physiol. 157: 445 462, 1949.

22. Samaja, M., P. E. Di Prampero, and P. Cerretelli. The role of 2,3-DPG in the oxygen transport at altitude. Respir. Physiol. 64: 191-202, 1986.

23. Samaja, M., E. Rovida, R. Motterlini, and M. Tarantola. The relationship between the blood oxygen transport and the human red cell aging process. In: Red Blood Cell Aging, edited by M. Magnani and A. De Flora. New York: Plenum, 1991, p. 115-123.

24. Samaja, M., E. Rovida, R. Motterlini, M. Tarantola, A. RUBINACCI, AND P. E. Di Prampero. Human red cell age, oxygen affinity and oxygen transport. Respir. Physiol. 79: 69-80, 1990.

25. Samaja, M., A. Rubinacci, A. De Ponti, and N. Portinaro. The effect of in vitro and in vivo cellular aging on the calcium transport in human inside-out red cell membrane vesicles. Biochem. Biophys. Res. Commun. 159: 432-438, 1989.

26. Samaja, M., A. Rubinacci, R. Motterlini, A. De Ponti, and N. PORTINARo. Red cell aging and active calcium transport. Exp. Gerontol. 25: 279-286, 1990.

27. SchmidT, W., D. Boning, and K. M. Braumann. Red cell age effects on metabolism and oxygen affinity in humans. Respir. Physiol. 68: 215-225, 1987. 
28. Seaman, C., S. Wyss, and S. Piomelli. The decline in energetic metabolism with aging of the erythrocyte and its relationship to cell death. Am. J. Hematol. 8: 31-42, 1980.

29. Strocchi, A., S. Schwartz, M. Ellefson, R. R. Engel, A. ME DINA, AND M. D. LEVITT. A simple carbon monoxide breath test to estimate erythrocyte turnover. J. Lab. Clin. Med. 120: 392-399, 1992.

30. Thompson, C. B., R. L. Galli, A. J. Melaragno, and C. R. VALERI. A method for the separation of erythrocytes on the basis of size using counterflow centrifugation. Am. J. Hematol. 17: 177-183, 1984.

31. West, J. B. Man at extreme altitude. J. Appl. Physiol. 52: 13931399,1982

32. Winslow, R. M. A model for red cell $\mathrm{O}_{2}$ uptake. Int. J. Clin. Monit. Comput. 2: 81-93, 1985.
33. Winslow, R. M., K. H. Chapman, C. C. Gibson, M. Samaja, C. C. Monge, E. GoldWasser, M. SHERPA, AND F. D. Blume. Different hematologic responses to hypoxia in Sherpas and Quechua Indians. J. Appl. Physiol. 66: 1561-1569, 1989.

34. Winslow, R. M., AND C. C. Monge. Hypoxia, Polycythemia, and Chronic Mountain Sickness. Baltimore, MD: Johns Hopkins University Press, 1987.

35. Winslow, R. M., C. C. Monge, E. G. Brown, H. G. Klein, F. H SARNQUist, N. J. WinsLOW, AND S. S. McKnEALLY. Effects of hemodilution on $\mathrm{O}_{2}$ transport in high-altitude polycythemia. $J$. Appl. Physiol. 59: 1495-1502, 1985.

36. Wolf-Priessnitz, J., J. C. Schooley, AND L. J. MahlmanN. Inhibition of erythropoietin production in unanesthesized rabbits exposed to an acute hypoxic-hypercapnic environment. Blood 52: 153-162, 1978.

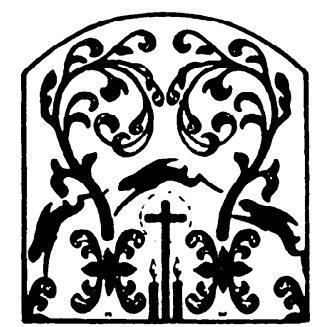

